Cad. Est. Ling., Campinas, 46(1):71-83, Jan./Jun. 2004

\title{
ALGUNS COMENTÁRIOS SOBRE AS MODALIDADES DE USO DA LÍNGUA-ESCRITA, FALA E ESCRITA EM TEMPO REAL
}

\author{
FÁBIO MADEIRA \\ (UNICAMP)
}

\begin{abstract}
This paper discusses the language modalities. I will first discuss spoken language - its characteristics and its uses. Next I will comment on written language and in the following section I will discuss the written language produced for synchronous communication through the internet. Besides having presented a new means of communication, the written language produced in real time has presented a new language modality that unites characteristics of both spoken and written language. I will argue that a dichotomy between the two language modalities does not justify and that the differences between spoken and written language are related to the function for which a text is produced.
\end{abstract}

\section{INTRODUÇÃO}

Este trabalho faz um sobrevôo pelas modalidades de uso da língua, iniciando pela língua falada, passando em seguida para língua escrita, para finalmente discutir a escrita em tempo real, um tipo particular de escrita usada para a comunicação síncrona através da internet.

Além de se apresentar como nova uma modalidade, a escrita em tempo real veio criar um novo tipo de interação entre emissor e receptor do texto escrito, já que a comunicação é feita sincronicamente e os faz produzir texto escrito semelhante àquele produzido para a comunicação em conversa presencial. Entretanto, é interessante notar que a escrita usada na internet em outros contextos de comunicação (comunicação assíncrona) tende também a aproximar-se da língua falada

\section{MODALIDADES DE LÍNGUA: DICOTOMIA OU CONTÍNUO TEXTUAL?}

Diferentes autores vêm, ao longo do tempo, apresentando visões diversas acerca das modalidades de uso da língua. Enquanto alguns procuram mostrar as diferenças entre os textos produzidos oralmente e aqueles produzidos por escrito, um outro grupo de autores e pesquisadores vêm questionando a visão dicotômica que é tomada por alguns autores ao tratar de textos escritos e falados. O questionamento desta visão serve de apoio a uma perspectiva teórica na qual a escrita e a fala são vistas dentro de um contínuo textual 
MADEIRA - Alguns comentários sobre as modalidades...

(Marcuschi 1995) ${ }^{1}$, em uma de cujas extremidades está situada a escrita formal e, na outra, a conversação. As modalidades, sob esta perspectiva, passam a ser vistas em relação dinâmica entre si, evitando, desta forma, uma dicotomia estanque entre o que pertence à língua falada e o que pertence à língua escrita. Aliás, evitar qualquer posição dicotômica entre as modalidades falada e escrita parece bastante pertinente se considerarmos que a modalidade escrita apareceu muito mais tarde, a partir da falada.

Meu interesse neste assunto veio a partir da surpresa que me causou a constatação de alguns autores (Chafe, 1984; Perera, 1984; Halliday, 1985; Chafe \& Tannen, 1987) de que a língua falada mostra-se gramaticalmente mais complexa do que a língua escrita. Segundo Halliday (1985), enquanto a escrita, ao apresentar textos de forma sinóptica, representa o fenômeno como um produto e, para isso, utiliza-se mais de substantivos, a fala tende a produzir textos de forma dinâmica, representando assim fenômenos como processos, representação esta que pede maior uso de verbos. Utilizar verbos envolve criar orações, que precisam ser interligadas, relacionadas, agrupadas. A gramática serve para ordenar essa seqüência de orações - para organizá-las, relacioná-las e agrupá-las - daí a complexidade gramatical da língua falada.

$\mathrm{Na}$ análise de textos produzidos para a comunicação assíncrona pela internet (via email), já foi constatada a semelhança com aqueles produzidos para a língua falada em conversações informais (Werry, 1996; Lamy \& Goodfellow, 1999; Weasenforth \& Biesenbach-Lucas, 1997 Müller-Harmann, 2000; Biesenbach-Lucas \& Weasenforth, 2001, Madeira, 2001). Se, assim como na língua falada, a porcentagem de verbos for também alta nos textos de mensagens de e-mail, pode ser válido investigar o uso de verbos na produção destes textos.

Passo abaixo a apresentar alguns aspectos da língua falada e da língua escrita para em seguida mostrar quais destes aspectos estão presentes nos textos produzidos para a comunicação mediada pelo computador.

\section{LÍNGUA FALADA}

A língua é, acima de tudo, um fenômeno oral. Através do som se iniciou a comunicação humana. O som é o ponto mais básico, não apenas para a comunicação, mas também, de uma maneira geral, para o pensamento, que se constrói pela língua falada (Ong, 1982). Havelock (1982) dá força a essa mesma posição:

"O fato biológico-histórico é que o homo sapiens é uma espécie que usa o discurso oral, manufaturado pela boca, para se comunicar. (...) o homem que lê, em contraste com o homem que fala, não é biologicamente determinado. Ele traz a aparência de um acidente histórico recente..."

(Havelock, 1982, p. 53-54)

\footnotetext{
${ }^{1}$ Marcuschi ressalta que sua visão das modalidades dentro de um contínuo não anula as diferenças entre a fala e a escrita, mas procura evitar uma dicotomia estanque, colocando-as sempre em uma relação dinâmica.
} 
Cadernos de Estudos Lingüísticos 46(1) - Jan./Jun. 2004

Não parece restar dúvida de que a origem de nossa língua, em todos os aspectos, inclusive o biológico é, basicamente, oral, portanto, a escrita coloca-se como um complemento à comunicação oral.

As diferenças entre fala e escrita são discutidas por vários autores sob diferentes aspectos e, por questões do espaço aqui disponível, cito apenas algumas daquelas que são consensuais entre alguns autores (Perera, 1984; Halliday, 1985; Hawkins, 1983; Tannen, 1992; Chafe, 1984; Chafe, 1994; Chafe \& Tannen, 1987). Entre as principais características da fala estão: 1) o fato de ser efêmera 2) tempo de produção (mais rápida que a escrita e mais lenta que a leitura ${ }^{2}$ ) 3) planejamento local 4) riqueza de prosódia e sinais paralingüísticos 5) igualdade de condições de produção para produtor e receptor da mensagem 6) colaboração entre os falantes na construção dos textos 7) uso maior de coordenação na ligação de orações 8) complexidade gramatical 9) utilização de repetição, redundância e paráfrase 10) justaposição de orações e 11) envolvimento.

Justaposição no texto oral foi identificada em uma pesquisa feita por Chafe (1984). $\mathrm{O}$ autor chamou de justaposição (tradução minha para "fragmentation") a expressão de mensagens através de frases sem conectores entre si: "Eu cheguei em casa, eu estava realmente exausto, Eu estava chupando um picolé, ... Eu estava sentado lá na minha cadeira, "(Chafe, 1984, p. 38). Os participantes da pesquisa expressaram-se através de orações justapostas, porém, utilizavam também conjunções coordenativas (mas, então, e) para introduzir idéias, como parte de um processo de editoração e organização da conversa em andamento. Justaposição de orações no texto da conversa foi também observado por Halliday (1985). Segundo o autor, o texto composto para a conversação é, como um todo, repleto de diferentes tipos de hesitações (falso começos, repetições, pausas preenchidas), hesitações estas que dominam a fala espontânea. Segundo Perera (1984), falso começo, preenchedores, pausas e repetições ocorrem na fala devido à falta de tempo para planejamento do texto produzido. São recursos que o falante usa para ganhar tempo e organizar suas idéias - quarenta por cento do tempo das mensagens da fala são pausas (Perera, op. cit.).

Além de justaposição, Chafe (1984) observou também que, na fala, os interlocutores buscam uma variedade de manifestações de envolvimento, utilizando-se de diferentes recursos: referências de primeira pessoa ( $e u$, me, nós, nos); emprego de marcadores conversacionais para garantir compreensão e monitorar o fluxo de informação ( $e$ u acho, me lembro, sabe?, entendeu?, quer dizer.., como assim?); uso de termos enfáticos visando expressar envolvimento entusiástico (teve atuação simplesmente fantástica; ela é mesmo muito burra; fiquei super animado) e uso de expressões indicando incerteza e imprecisão (levou um tipo de bolsa; esperei mais ou menos duas horas).

A repetição é outra característica no texto falado, e já foi assunto discutido por lingüistas renomados (Koch, 1998; Tannen, 1992). Koch defende que a repetição tem

${ }^{2}$ Chafe (1994) comenta algumas pesquisas quantitativas indicando que falamos aproximadamente 180 palavras por minuto, escrevemos pelo menos dez vezes mais lentamente e que a leitura é ainda muito mais rápida que a fala - lemos de 200 a 400 palavras por minuto, dependendo da habilidade de cada pessoa. 
MADEIRA - Alguns comentários sobre as modalidades...

papel importante na construção do texto falado e discute esta característica sob diferentes quando adultos, temos prazer em repetir provérbios, frases feitas, slogans, enunciados de artistas de TV. Sem falar nos discursos formulaicos; pares adjacentes como cumprimentos, despedidas e fórmulas de cortesia muitas vezes exigem repetição. Sob o aspecto cognitivo, Koch (op. cit.) lembra que, particularmente no processo de aprendizagem de línguas, a repetição tem papel relevante. Itens novos apresentados ao aprendiz de uma língua estrangeira e relacionados àqueles por ele já conhecidos, quando usados com freqüência, ajudam a criar categorias que auxiliam no processo de aprendizagem. Koch discute vários tipos de repetições e as divide em dois tipos: alo-repetição (repetições da fala do outro) e auto-repetição (repetições do próprio falante). A autora comenta vários casos em cada um dos tipos de repetição e mostra como cada uma delas tem sua função na produção do texto: "muitas das auto-repetições no nível discursivo desempenham funções semelhantes (intensificação, iteração, continuação) (Koch, 1998: 104). Na discussão das alo-repetições, a autora atentou às funções interacionais deste tipo de repetição no discurso, entre as quais a garantia ou entrega de turno, expressão de surpresa, descrença, provocação e enfrentamento, preenchimento de pausas e confirmação de uma fala.

Tannen (1992) também discutiu a função interacional da repetição na língua falada e considerou a repetição como recurso de envolvimento na fala. A autora defendeu que repetição é recurso usado entre interlocutores como estratégia de envolvimento interpessoal, recurso facilitador da compreensão da mensagem, já que exige do ouvinte menos esforço para o processamento da mensagem e dá ao falante oportunidade de melhor organizar suas idéias. Tannen (op. cit.) mostrou diversos tipos de repetições empregadas na fala, que incluem redundância, repetição com variações que, segundo a autora, são as mais comuns (perguntas transformadas em afirmações ou afirmações transformadas em perguntas), mudanças de pronomes ou tempo verbal e paráfrase. Os dois últimos tipos (mudança de pronomes e tempo verbal e paráfrase) como forma de repetição envolvem mudanças estruturais ou gramaticais no texto, o que o torna mais gramaticalmente complexo.

A complexidade gramatical foi apresentada por Halliday (1985) como uma das mais importantes características da fala. Conforme expus acima, o autor mostrou que, ao falar, tendemos a transmitir as mensagens como processos (ao contrario da escrita, que as transmite como produto), e processos são dinâmicos. A apresentação dinâmica do texto leva à utilização de quantidade maior de verbos (em oposição às nominalizações feitas na língua escrita) que, por sua vez, pressupõe a construção de orações envolvendo agentes, ações e resultados. Visando exemplificar a complexidade gramatical da língua falada, o autor comparou os textos abaixo:

escrito

Cada visita anterior havia me deixado com um sentimento de inutilidade de outra ação de minha parte falado

Toda a vez que eu tinha ido lá antes, eu acabava sentindo que seria inútil se eu tentasse fazer qualquer outra coisa. 
Cadernos de Estudos Lingüísticos 46(1) - Jan./Jun. 2004

Por que a tecnologia melhorou, é menos

Aperfeiçoamentos na tecnologia reduziram os riscos e os altos custos associados com arriscado do que era quando você os instala ao mesmo tempo, e também não custa tanto.

instalação simultânea.

(Halliday, 1985: 81 - grifos meus)

Os grifos nos excertos acima foram feitos buscando mostrar como é maior a quantidade de verbos nos textos falados.

É também característica importante da fala a interação face a face entre os interlocutores. A fala, principalmente na conversação, é uma atividade complexa e multifacetada, onde os interlocutores estão envolvidos em um processo colaborativo no qual negociam tomadas de turnos e compreensão através da escolha de palavras e da experiência que temos de situações semelhantes (Marcuschi, 1995; Gumperz, 1982). Não se pode deixar de fora deste processo os sinais paralingüísticos, tais como gestos, expressões faciais e pausas, usados na comunicação oral para sinalizar emoções e reações, que servem também como organizadores das tomadas de turnos, dão rumo à comunicação. O texto falado ocorre, de forma geral, online, ou seja, é criado no momento da conversação, acontece de acordo com as reações dos interlocutores, e sinais paralingüísticos servem como recursos de auxílio no processo colaborativo estabelecido entre os interlocutores: sinalizam (in)compreensão, fazem fluir a troca de informações com mais facilidade.

O processo colaborativo entre os falantes os faz interagir a todo momento, faz com que construam a comunicação mutuamente, exercitem escolhas, tanto de significados quanto na maneira de comunicar os significados escolhidos (Bygate, 1998). A interação na fala é direta e serve como recurso direcionador da comunicação. Chafe (1984) explica que o texto falado é reflexo de unidades comunicativas, que se formam na mente em vários pequenos blocos, e algum tipo de mecanismo interno faz com que construamos e organizemos o texto praticamente ao mesmo tempo em que falamos. Este processo leva à produção de um texto sempre passível de mudanças - reformulações causadas não apenas pela organização, mas também pela interação com o ouvinte.

Passo em seguida a discutir a produção de texto escrito, mostrando como o planejamento nos faz integrar idéias e produzir textos mais compactados e lexicalmente densos.

\section{LÍNGUA ESCRITA}

Comecei este trabalho discutindo a língua falada e mostrando que a origem da língua é, basicamente, oral. Há que se considerar, no entanto, o outro lado da questão. Mesmo que traga a "aparência de um acidente histórico" (Havelock, 1982: 54), o homem que lê e escreve existe, convive com aviões e computadores, entre várias outras inovações tecnológicas, inovações estas que deram início a um processo de desenvolvimento irreversível, no qual a escrita tem papel importante. 
MADEIRA - Alguns comentários sobre as modalidades...

Assim como a língua falada apresenta características peculiares, a escrita também tem características próprias ${ }^{3}$, entre as quais estão: permanência, planejamento no preparo, possibilidade de releitura e reformulação, integração, distanciamento, clareza, maior freqüência de subordinação de orações e densidade lexical.

A situação física de produção é fator importante na elaboração do texto escrito. Um aspecto relevante nesta situação é a falta de intercâmbio imediato entre produtor e receptor do texto (o que Chafe (1994) chama de "desituatedness"). Perera (1984), baseada neste aspecto, refere-se à escrita como atividade isolada e solitária. Uma vez que o produtor da mensagem não tem contato direto com o receptor, não dispõe de sinais paralingüísticos para deixar mais claro seu texto - tudo que tem são sinais gráficos no papel - é forçado a ser claro, daí a característica de clareza da escrita. Perera (op. cit.) citou como exemplo disso o mal entendido da então primeira dama dos Estados Unidos, Nancy Reagan, que ocorreu em uma entrevista falada: "The TV interrogator burbled, "And now Mrs. Reagan, tell us about your famous gaze". Nancy's tight smile tightened into invisibility. "Gays?" she said coldly". (Perera, 1984, p- 179). Só a ortografia facilitaria a compreensão e pouparia Nancy do constrangimento. Outros recursos da língua escrita, tais como parênteses, notas de rodapé, títulos, formato de texto e aspas nos são de tão grande utilidade que, às vezes, os importamos da escrita e mostramos oralmente ou através de gestos. Como exemplo mais comum, pode-se citar o uso de aspas - não é raro falantes citarem as aspas oralmente e/ou através de gestos para deixar claro que estão repetindo palavras de outros.

Subordinação de orações, outra característica da língua escrita, é também uma maneira de tornar o texto mais explícito. Enquanto na fala as orações são mais freqüentemente organizadas por coordenação, na escrita a tendência é organizá-las por subordinação, estratégia que serve como recurso para colocarmos idéias mais importantes em destaque. Halliday (1985) dá exemplos de como o escritor pode, de acordo com o que deseja enfatizar, destacar uma informação ou outra através da ordem por ele escolhida dos elementos das orações. Subordinação é resultado, basicamente, do tempo disponível para a elaboração do texto, que nos permite integrar idéias e dá ao texto escrito textura integrada (Perera, 1984).

Uma das características que Chafe (1984) constatou em textos escritos foi integração, que consiste em reunir mais informações dentro de uma unidade comunicativa; a subordinação de orações foi incluída pelo autor como um dos mecanismos de integração. Baseado em comparações entre as velocidades da fala, escrita e leitura, o autor concluiu que, enquanto escrevemos, nossos pensamentos continuam avançando, e de maneira muito mais rápida do que podemos registrá-los por escrito. Escrevendo, temos a chance de integrar uma série de idéias em um só bloco, diferentemente do que ocorre na fala, quando pensamos e falamos ao mesmo tempo. A integração de idéias em um bloco resulta em um texto mais compacto e com maior número de palavras de conteúdo, ou seja, com maior densidade lexical.

\footnotetext{
${ }^{3}$ Vale lembrar que as características expostas aqui da língua falada e da língua escrita não são absolutas de uma modalidade ou de outra. Diferentes textos escritos podem ser criados com características do texto falado, assim como muitos textos falados podem ser construídos com características de um texto escrito.
} 
Cadernos de Estudos Lingüísticos 46(1) - Jan./Jun. 2004

Densidade lexical foi considerada a diferença mais característica entre a escrita e a fala (Halliday, 1985). Quando o autor observou maior tendência para uso de verbos e palavras gramaticais na língua falada, observou maior uso de palavras de conteúdo na língua escrita. Tanto Perera (1984) quanto Chafe (1984) observaram também maior número de palavras de conteúdo na língua escrita e atentaram para a tendência ao uso de substantivos nesta modalidade. Nominalizações foi um dos mecanismos de integração da língua escrita citados por Chafe (op. cit. ). Halliday (1985) deu um passo adiante na discussão e ressaltou que, além de verbos, o escritor pode fazer uso de outros termos como substantivos, com a intenção de enfatizar uma informação específica.

Outra característica da língua escrita que Chafe (op. cit.) colocou, juntamente com integração, foi "distanciamento" (tradução minha para "detachment"), que ele contrasta com o "envolvimento" da língua falada. Segundo o autor, este é o recurso usado para distanciar o texto produzido de qualquer evento ou situação específica. Como mecanismos de distanciamento, Chafe citou o uso de voz passiva e também nominalização, que passou assim a ser considerado mecanismo tanto de integração quanto de distanciamento. Alguns anos mais tarde, quando comentou o trabalho de diversos autores que discutiram as diferenças estruturais das modalidades de uso de língua (Chafe \& Tannen, 1987), Chafe ${ }^{4}$ viu confirmadas suas constatações: tendência de justaposição de orações e envolvimento na língua falada e integração e distanciamento na língua escrita ${ }^{5}$.

Passo abaixo a comentar a produção do texto escrito veiculado pela internet, visando mostrar que, neste novo contexto de comunicação, a língua escrita aproxima-se da língua utilizada em textos falados.

\section{A LÍNGUA ESCRITA QUASE FALADA DA INTERNET}

A comunicação por escrito em tempo real feita pela internet veio introduzir um novo contexto de comunicação, no qual os interlocutores "conversam" por escrito. Não causa surpresa, portanto, que a língua escrita usada na comunicação síncrona via internet aproxime-se da língua falada usada na conversa presencial, já que ambos os processos ocorrem em tempo real. Apesar de estarem distantes, os interlocutores enfrentam, basicamente, as mesmas condições de produção - usam o mesmo meio e produzem texto sincronicamente - porém, o fato de não compartilharem o mesmo espaço físico os leva a um tipo novo de editoração de texto. Através deste novo meio, busca-se clareza nos textos escritos das mensagens sem se ter disponível o tempo necessário para o planejamento que a escrita normalmente exige. A produção de um texto escrito com clareza sem planejamento

${ }^{4} \mathrm{O}$ artigo consiste em dois textos, um de Chafe e outro de Tannen. Chafe tratou das diferenças estruturais de textos orais e escritos, enquanto Tannen discutiu as influências contextuais na produção de textos das duas modalidades.

${ }^{5}$ Um dos autores resenhados por Chafe afirmou ter constatado características de distanciamento também nos textos falados. 
MADEIRA - Alguns comentários sobre as modalidades...

só é possível na Comunicação Mediada por Computador $\left(\mathbf{C M C}^{6}\right)$ graças à interação direta entre os interlocutores.

Pelittieri (2000) encontrou neste contexto de comunicação praticamente o mesmo modelo de interação que ocorre na conversação face-a-face. Os interlocutores interagem negociando significados e se engajam num esforço mútuo para garantir compreensão. A interação direta e o esforço mútuo na busca de compreensão parecem mostrar que a colaboração entre falantes, característica da língua falada, está também presente na comunicação síncrona feita por escrito.

Comunicar-se por escrito em tempo real é uma função verdadeiramente nova da escrita e é curioso como, na comunicação por este meio, os usuários parecem utilizar a escrita (adaptá-la, na verdade) de maneira que se aproxime ainda mais da língua falada usam sinais de pontuação como tentativa de enfatizar a entonação que teria na fala: $o$ que????; isso mesmo!!!!! ou ainda procuram grafar sons "Ah"; "UAU!!!". Usam também repetição, geralmente de vogal, para indicar alongamento de som (“Xiiiiiiiiiiii!!!"). É interessante notar como as tecnologias criadas para a comunicação por escrito tendem a se aproximar das qualidades fonéticas da língua. Isso faz lembrar que, embora os primeiros sinais da escrita tenham sido criados a partir de imagens referindo-se a entidades do mundo real, no decorrer do tempo, passaram a ser relacionadas com os sons das palavras que representavam (Halliday, 1985). Passados milhares de anos desde a invenção da escrita, a comunicação por escrito em tempo real utiliza a escrita para um novo tipo de comunicação, através da qual os usuários buscam diferentes maneiras de representar o som. E inovam ainda mais; de modo bastante criativo, usam sinais de pontuação para procurar expressar aspectos paralingüísticos. E, de tão freqüentemente usados, são automaticamente transformados pelas máquinas mais modernas: dois pontos, travessão e parentes : - ) transforma-se em (:) assim como : - ( se transforma em $*$. Nas chamadas salas-de-batepapo, o usuário tem à sua disposição imagens que transmitem reações e sentimentos:

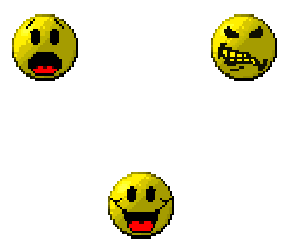

Além de interação direta entre os interlocutores, observa-se também na comunicação por escrito em tempo real a presença de manifestações de envolvimento, que Chafe (1984) afirma ser recurso de aproximação entre falante e ouvinte, mesmo em ambiente com grau maior de formalidade. $\mathrm{O}$ uso das mesmas expressões indicando incerteza e imprecisão (um tipo de, uma espécie de), assim como termos enfáticos (muito, totalmente) apresentados por Chafe (op. cit.) como recursos de envolvimento, foi observado nos textos de discussões entre profissionais das mais diversas áreas e tratando dos mais diversos assuntos (Collot \& Belmore, 1993).

\footnotetext{
${ }^{6}$ Entende-se aqui CMC feita por escrito.
} 
Cadernos de Estudos Lingüísticos 46(1) - Jan./Jun. 2004

Comentei acima que a complexidade gramatical, como característica da língua falada, é conseqüência da expressão da mensagem como um processo (Halliday 1985) e, para representar processos, precisamos de verbos. Alguns autores já observaram esta característica também na CMC síncrona (Kern, 1995; Chapelle, 1998; Pelittieri, 2000). Kern (op. cit.), comparando uma discussão feita pela CMC com uma discussão sobre o mesmo assunto feita presencialmente, observou ainda maior uso de formas verbais na discussão feita pela CMC do que na conversa presencial.

No que se refere ao tempo de produção, há que se considerar a diferença de velocidade da escrita feita a mão e na CMC. A digitação é muito mais rápida do que a escrita a mão e são utilizadas abreviações típicas do meio, tais como "vc, pq", ou, em inglês, "u" e "r", abreviando "you" e "are", respectivamente, entre várias outras (Paolillo, 1999). Além disso, as mensagens, de forma geral, são relativamente curtas. É claro que, mesmo assim, os tempos de produção de textos na fala e na escrita são incomparáveis, porém não se pode deixar de considerar este conjunto de fatores na escrita dos textos para a CMC. Se usamos tantas abreviações, a digitação é mais rápida que a escrita a mão e as mensagens são relativamente curtas, a velocidade na produção do texto escrito, neste contexto de comunicação, é certamente maior.

A curta extensão das mensagens da CMC sincrônica é resultado do menor tempo disponível para o planejamento do texto. É bem verdade que a produção de mensagens curtas pode exigir ainda maior planejamento, porém, neste contexto de produção, planejamento e extensão das mensagens estão relacionados. Embora seja possível planejar o texto antes de escrevê-lo, o planejamento é bastante menor, por razões óbvias. Em primeiro lugar, a comunicação cessaria, por tédio entre os interlocutores, se precisassem esperar pelo planejamento que a escrita normalmente exige. Em segundo lugar, os participantes das salas de bate-papo estão em constante competição por atenção, portanto, mensagens longas seriam inadequadas para um meio que se aproxima do bate-papo presencial (Werry, 1996).

Das características da fala acima expostas, apenas efemeridade e repetição não foram apontadas nas pesquisas comentadas. Creio que estas características não tenham sido constatadas por estarem inter-relacionadas. Se, segundo Tannen (1992), repetições são utilizadas pelos falantes como recurso facilitador para a compreensão da mensagem, já que exige do ouvinte menos esforço para a compreensão. $\mathrm{Na} \mathrm{CMC}$, este recurso não se faz necessário, pelo fato do texto da conversa não ser efêmero; é possível ler e reler as "falas" do interlocutor utilizando-se da barra de rolagem. Aliás, este é um recurso precioso neste tipo de comunicação, já que pode promover ainda maior compreensão entre os "falantes".

Conforme comentei acima, não causa espanto constatar as mesmas características da fala na CMC síncrona, afinal, seja por um meio ou outro, os interlocutores estão conversando. Esta não é, no entanto, a única modo de comunicação por escrito via internet - é possível comunicar-se também assincronamente por e-mail. Aliás, o e-mail é a forma mais comum de CMC (Chen, 1998).

Despertou a atenção de alguns pesquisadores (Madeira, 2001; Warschauer, 1998; Müller-Hartmann, 2000; Gains, 1999; Lamy \& Goodfellow, 1999; Weasenforth \& Biesenbach-Lucas, 97; Biesenbach-Lucas \& Weasenforth, 2001), o fato de que a língua 
MADEIRA - Alguns comentários sobre as modalidades...

usada nos textos de e-mails difere daquela produzida para textos escritos usados na comunicação tradicional, como cartas, por exemplo ${ }^{7}$. Gains (1998) analisou a linguagem utilizada nos textos de e-mails nos contextos empresarial e acadêmico e constatou que o formato, em ambos os contextos, difere daquele das cartas formais. Não havia nos textos das mensagens nenhum tipo de abertura e, para o fechamento, era usado apenas o nome do emissor ${ }^{8}$ ou, no caso de pedidos, um simples obrigado9. O autor observou ainda predominância de uso de linguagem com menor grau de formalidade na troca de e-mails, independente da relação entre emissor e receptor.

Além de diferir dos textos escritos em formato e grau de formalidade, a linguagem dos textos de e-mails apresenta também características dos textos da língua falada em conversações presenciais. Observa-se a presença de marcadores conversacionais (Gains 1999), de perguntas diretas ao receptor da mensagem e de respostas sem ocorrência de perguntas, como se o escritor estivesse conduzindo um diálogo com um interlocutor ausente (Gains, op. cit. p. 93). Muller-Hartmann (2000) observou ainda, nos textos de e-mails, o uso de expressões indicando envolvimento, incerteza e imprecisão, de termos enfáticos e grande quantidade de orações justapostas. Hesitações e pausas são também freqüentemente expressas na CMC através de reticências (Negretti, 1999).

Lamy \& Goodfellow (1999) deram um passo adiante na discussão. Os autores constataram tendência à utilização de linguagem dialógica nos textos de e-mails, com todas as características da fala comentadas acima, e observaram como, através da comunicação por e-mail, unem-se os processos de reflexão consciente com aqueles de interação simultânea: "Típico do tipo de interação gerada nestes sistemas é uma espécie de conversa "em câmera lenta", na qual as mensagens e suas respostas podem estar separadas em vários dias." (Lamy \& Goodfellow, 1999 - p.45). Outros autores já fizeram comentários semelhantes sobre a comunicação por este meio. Gains (1999:81) referiu-se ao meio como "pseudo-conversacional"; Müller-Hartmann (2000, p.137) chamou essa comunicação como "conversa escrita"; e Weasenforth \& Lucas (1997) chamaram os textos de e-mails de escrita em tempo real, apesar da comunicação não ocorrer em tempo real.

A CMC, seja ela feita sincrônica ou assincronicamente, parece ter se colocado não apenas como uma nova modalidade, mas também nos levou a produzir linguagem de maneira nova, adequada a um meio de comunicação igualmente novo. Veio, acima de tudo, dar força à posição de Marcuschi $(1994,1995)$, que defende a visão das modalidades dentro de um contínuo tipológico, sem estabelecer uma dicotomia estanque entre o que pertence à língua escrita e o que pertence à língua falada.

${ }^{7}$ O correio tradicional já é chamado de snailmail (snail significa, em inglês, lesma) para contrastar com a rapidez do e-mail (correio eletrônico).

${ }^{8} \mathrm{O}$ nome do emissor também é freqüentemente omitido.

${ }^{9}$ Embora o autor não tenha considerado as diferenças que encontrou nos textos de e-mails em contexto empresarial, outros autores já defendem que as mudanças são tantas que um novo registro pode estar emergindo. Para maiores informações veja Gimenez, 2000. 


\section{CONSIDERAÇÕES FINAIS}

Procurei, neste trabalho, mostrar que, apesar de a escrita e a fala apresentarem diferenças, tais diferenças estão relacionadas à função para a qual o texto específico for criado. Halliday \& Hassan (1989) afirmam: "texto é... lingua em funcionamento, que tem alguma função dentro do contexto de situação.” (p. 52). As funções para as quais usamos a escrita e a fala mudam em nossa cultura (Halliday, 1985), assim como muda a maneira como falamos e escrevemos. Como exemplos concretos disso posso citar dois: 1) escrevo este texto em primeira pessoa, o que, há não muito tempo, era inaceitável na escrita acadêmica; 2) no meio empresarial, prefere-se usar o e-mail, apesar da facilidade e rapidez da comunicação por telefone (Warschauer, 2000).

Novas tecnologias vêm repetidamente nos apresentando novas realidades. Microfones, telefones e gravadores de voz nos fizeram buscar outras maneiras de produzir textos orais. Os computadores apresentaram uma nova maneira de ler (Halliday, 1985) e de escrever (Warschauer, 1999). A internet foi ainda mais longe. Introduziu um novo uso da escrita, um novo meio de comunicação e uma nova modalidade de língua que une aspectos da escrita e da fala: "A divisão histórica entre a fala e a escrita foi ultrapassada com os aspectos interacional e reflexivo da língua em um único meio: CMC" (Warschauer, 1997:472).

\section{REFERÊNCIAS BIBLIOGRÁFICAS}

BIESENBACH-LUCAS S. \& WEASENFORTH, D. (2001). E-Mail And Word Processing In The Esl Classroom: How The Medium Affects The Message. Language Learning \& Technology, vol. 5 n 1 (p. 135-165).

BYGATE, M. (1998). Theoretical Perspectives on Speaking. Annual Review of Applied Linguistics, n. 18, pg. $20-42$.

CHAFE, W. (1984). Integration and Involvement in Speaking, Writing and Oral Literature. In: Tannen, D. (org.). Spoken and Written Language: Exploring Orality and literacy. Norwwod, New Jersey.

Chafe, W. \& TANNEN, D. (1987). The Relation between Written and Spoken language. Annual Review of Anthropology, vol. 16.

CHAFE, W. (1994). Discourse, Consciousness, and Time. The flow and Displacement of Conscious Experience in Speaking and Writing. The University of Chicago Press.

CHAPELLE, C.A. (1998). Multimedia Call: Lessons to be learned from research on instructed SLA. Language Learning and Technology, vol. 2 n¹, p. 22 - 34. Online. Disponível na Internet http://llt.msu.edu/vol2num1/ article1/index.html.

CHEN, G. (1998). Intercultural Communication via E-mail Debate. The Edge: The E-Journal of Intercultural Relations, vol. 1, nº4. Disponível na Internet http://www.hart-li.com/biz/theedge.

COLlot, M. \& BELMORE, N. (1993). Eletronic Language: A new Variety of English. In: Aarts J., Haan P., Oostdijk (org.), English Language Corpora: Design and Exploitation. 
MADEIRA - Alguns comentários sobre as modalidades...

GAINS, J. (1999). - Eletronic Mail - A New Style of Communication or just a New Medium?: An Investigation into the Text Features of E-mail. English For Specific Purposes, vol. 18, n. 1, p.81-101.

GIMENEZ, J.C. (2000).Business e-mail Communication: Some Emerging Tendencies in Register. English for Specific Purposes, 19, p. 237-251.

HALLIDAY, M.A.K. (1985). Spoken and Written language - Oxford University Press.

HALLIDAY, M.A.K. \& HASSAN, R. (1989). Language, context and text: aspects of language in a social semiotic perspective. Oxford University Press.

HAVELOCK, E. (1982). A Revolução da Escrita na Grécia e suas Conseqüências Culturais. Rio de Janeiro, Paz e Terra.

HAWKINS, E. (1983). Spoken and Written Language. Cambridge University Press.

KOCH, V.I. (1998). O Texto e a Construção dos Sentidos. São Paulo: Contexto.

KERN, G.R. (1995). Restructuring Classroom Interaction with Networked Computers: Effects on Quantity and Characteristics of Language Production. The Modern Language Journal, 79, IV, pg. 457-476.

LAMY, M.N. \& GOODFELLOW, R. (1999). Reflective Conversation in the Language Classroom. Language Learning \& Technology, vol. 02, p.43-62.

MADEIRA, F. (2001). A Comunicação em Língua Estrangeira Mediada Pelo Computador: O Impacto Na Precisão. Dissertação de Mestrado apresentado ao IEL Instituto de Estudos da Linguagem, UNICAMP. Também disponível em http://www.rau-tu.unicamp.br/nourau/sbu/document/ ?code $=$ vtls000228723.

MARCUSCHI, L.A. (1994). Contextualização e Explicitude na Relação entre Fala e Escrita. Conferência apresentada no I Encontro Nacional Sobre Língua Falada e Ensino, UFAL, Maceió, 14-18 de março. (1995). Oralidade e Escrita. Conferência. I Colóquio Franco-Brasileiro sobre Linguagem e Educação - UFRN, Natal, 26-28 de junho, 17p

MÜLLER-HARTMANN. (2000). The Role of Tasks in Promoting Intercultural Learning in Eletronic learning Networks. Language Learning \& Technology, vol. 4, nº 2, p - 129-147.

NEGRETTI, R. (1999). Web-Based Activities and SLA: a Conversation Analysis Research Approach. Language Learning \& Teaching, vol. 3, nº 1 , p. 75-87.

PAOLILLO, J. (1999). The Virtual Speech Community: Social Network and Language Variation on IRC. Journal of Computer-Mediated Communication, vol. 4, $\mathrm{n}^{\circ} 4$

PELITTIERI, J. (2000). Negotiation in Cyberspace: The Role of Chatting in the Development of Grammatical Competence. In: Mark Warschauer and Richard Kern (org.) Network-based Language Teaching: Concepts and Practice., p. 59-86. Cambridge University Press.

PERERA, K. (1984). Children's Writing and Reading - Analysing Classroom Language. Blackweel \& Deutsch.

TANNEN, D. (1992). Talking Voices - Repetition, dialogue, and imaginary in conversational discourse. Cambridge University Press.

WARSCHAUER, M. (1997). Computer-Mediated Collaborative Learning: Teory and Practice. The Modern Language Journal, n. 81, IV, pg. 470-481. 
(1998). Interaction, Negotiation and Computer-Mediated Learning. In: M. Clay (Ed.), Practical applications of educational technology in language learning. Lyon, France: National Institute of Applied Sciences.

(1999). Surveying the Terrain of Literacy in Eletronic Literacies: Language, culture, and power in online education. Mahwah. NJ: Lawrence Erlbaum Associates.

(2000b). The Death of Cyberspace and the Rebirth of CALL. Versão editada de palestra dada em "IATEFL and ESADE Conference", em 2 de julho de 2000, Barcelona, Espanha.

WEASENFORTH, D. \& BIESENBACH-LUCAS, S. (1997). E-mail and wordprocessed texts of non-native speakers: Distinguishable text types?. Disponível em http://www.gwu.edu/ washweb/lucas.html.

WERRY, C.C. (1996). Linguistic and interactional features of Internet Relay Chat. In: S. C. Herring (org.), Computer-mediated Communication: Linguistic, Social and Cross-cultural Perspectives. Amsterdam: Benjamins, p.47-63. 